\title{
A AUTENTICIDADE DA PALAVRA DA CRIANÇA COMO INDÍCIO DE INSUBORDINAÇÃO CRIATIVA
}

\author{
THE AUTHENTICITY OF THE CHILD'S WORD AS A CLAUSE OF CREATIVE \\ INSUBORDINATION
}

\author{
Solange Aparecida Corrêa \\ Universidade Cruzeiro do Sul / solangeapc600@gmail.com
}

\begin{abstract}
Resumo
O objetivo deste artigo é apresentar situações escolares do cotidiano atribuindo relevância sobre $o$ trabalho em grupo e a mediação do professor a partir de narrativas das crianças. São atividades que estão relacionadas com a matemática e ilustração de texto. A faixa etária das crianças é de 7/8anos e as aulas analisadas aconteceram numa classe de 30 alunos do $2^{\circ}$ ano do Ensino Fundamental em uma escola privada da cidade de Campinas. A importância das interações sociais no grupo pode suscitar indícios de insubordinação criativa quando alguns alunos se posicionam a favor de seus interesses e do grupo. Essas interações tem sentido quando o professor legitima o que a criança fala sobre si, sobre o outro, sobre a escola apoiando-a a realizar uma leitura de mundo construída coletivamente. Nessa perspectiva se caracteriza a pesquisa (auto)biográfica com crianças. A postura do professor quando coloca o aluno no centro do processo educacional, desafiando-o a resolver problemas e a criar propostas para a solução, também evidencia indicativos de insubordinação criativa do professor. Para a análise desses argumentos, consideram-se como inferências teóricas que o ser humano transforma o meio para atender as suas necessidades básicas e transforma-se a si mesmo. As conclusões evidenciam que existem ações factíveis de insubordinação criativa.
\end{abstract}

Palavras-chave: insubordinação criativa, argumentação, pesquisa (auto) biográfica, infância.

\begin{abstract}
The purpose of this article is to demonstrate situations in school everyday by assigning relevance of the work in the group and the mediation of the teacher from the narratives of the children. They are activities that are related with mathematics and illustration of the text. The value of social interactions in the group are relevant to elicit evidence of creative insubordination when some of the students argue in favour of their interests. These interactions have meaning when the teacher legitimizes what the child talks about himself, about the other, about the school apoiandoa to perform a reading of the world is constructed collectively. In this perspective characterizes the search (auto)biographical with children. The attitude of the teacher when it places the student at the centre of the educational process, challenging him to solve problems and to create proposals for the solution, also
\end{abstract}


evidence indicative of insubordination creative teacher. For the analysis of these arguments, it is considered as inferences theory that the human being transforms the environment to meet their basic needs, and transforms himself. The findings show that there are actions feasible insubordination creative.

Keywords: creative insubordination, argumentation, research, (auto) biographical, childhood.

\section{Introdução}

Esse artigo se apoia em narrativas orais das crianças transcritas pela própria professora em uma classe de 30 alunos do $2^{\circ}$ ano (7/8anos) do Ensino Fundamental em uma escola privada da cidade de Campinas.

Configura-se a metodologia pautada em reflexões de experiências vividas que se manifesta desde a infância, daí a importância de escutar o aluno e dar sentido a partir do que nos conta como fonte de pesquisa (auto)biográfica em Educação. (Passeggi, 2014).

A mediação do professor manifesta-se como facilitador para investigar o que as crianças pensam e falam a respeito das diversas situações-problema apresentadas, fazendo questionamentos gerando a possibilidade de se criar e aumentar a autoconfiança nos aprendizes.

Serão narradas situações de sala de aula pautadas em trabalhos em equipe nas quais a professora mostra a intencionalidade de investigar o porquê de algumas atitudes e levando as crianças a refletirem sobre suas próprias experiências. Essas reflexões nos mostram evidências de que é possível mudar atitude em favor de si próprio visando o seu bem estar, a favor do outro, mostrando indícios de insubordinação criativa.

O uso de fontes (auto)biográficas como método de pesquisa é uma prática muito usada pois as narrativas (auto)biográficas fornecem um material precioso para a investigação. ( Passeggi, M. C.;Silva V. B. [M. C. Passeggi], 2010)

\section{O valor do trabalho em grupo}

Considerando o valor das interações sociais, construir conhecimento exige uma ação partilhada, pois é através dos outros que as relações entre sujeito e objeto de conhecimento são estabelecidas (Rego, T. C. [Vigotski], 1995). No contexto escolar emergem as relações entre os alunos e entre os alunos e o professor. 
De acordo com Lopes e D’Ambrosio (2015), o professor é o elemento-chave na criação do ambiente que se vive na sala de aula: cabe a ele a responsabilidade de propor e organizar tarefas, bem como de coordenar o desenvolvimento das atividades dos alunos.

O professor também precisa deixar de ser somente um mero transmissor de informações e passar a ser um pesquisador juntamente com seus alunos, questionando e provocando a curiosidade e fazendo com que pensem sobre as diferentes formas de apropriação do conhecimento para que possam aplicá-lo na realidade em que vivem. A mediação do professor se faz importante e trabalhar com grupos heterogêneos levando em consideração a individualidade de cada um, possibilita avanços na aprendizagem e na formação de cidadania.

Ao planejar suas ações, o professor deve considerar o desenvolvimento de seus alunos e intervir na zona de desenvolvimento próximo, provocando avanços que não ocorreriam espontaneamente (Shuare, M. [Vigotski], 2016). A criança não percorre o caminho do seu aprendizado sozinha e alguns procedimentos como experiência concreta, fornecimento de pistas, instruções, propor situações-problema desafiadoras e deixar que os alunos elaborem suas soluções são estratégias que colaboram para um desenvolvimento da sua autonomia.

Dessa forma, o trabalho em grupo se torna o centro de planejamento do professor, pois a interação entre as crianças é fundamental para o desenvolvimento das mesmas.

De acordo com Corsaro, (MÜLLER , F.; CARVALHO, A. M. A [Corsaro], 2009), ensino deve provocar avanços através da interação social entre o professor e seus alunos e a interação entre os pares, sob sua orientação:

.... foco de estudos sobre a criança deve ser posto em suas atividades coletivas, onde ela participa junto com outros pares de idade na produção de rotinas culturais em contextos sócio-histórico-culturais concretos... Elas asseguram a seus integrantes não só um conhecimento comum, mas a segurança de pertencer a um grupo e partilhar da identidade que o mesmo confere a seus membros e de negociar a sua própria identidade dentro do grupo. São rotinas desejadas pelas crianças pelo prazer de poder realizar coisas junto com companheiros. (p.60)

Essa proposta de trabalho considera o aluno e seu grupo como protagonistas da própria aprendizagem, revelando um ensino com significado e motivador para o educando e seu educador.

O professor precisa considerar que todos os seus alunos devem ser reconhecidos. De acordo com Hooks (2013), o professor precisa valorizar a presença de cada um. Todos são importantes na construção de um espaço comunitário e no esforço coletivo há grande probabilidade de gerar um ambiente de aprendizado com significado.

Considerando essa interação entre os professores e alunos e entre os próprios alunos, relatamos aqui situações de ensino em que se priorizam as diferentes ideias de pensamento na resolução de problemas. 


\section{llustrando a história da escola}

A primeira atividade é uma ilustração feita em grupos a partir da leitura de um texto informativo sobre a história da escola em que estudam. Ler esse texto possibilitou reflexões sobre o contexto da origem da escola e comparações entre época distintas através da escrita e imagens propostas no texto.

Após a leitura desse texto, os alunos foram organizados em grupos e cada grupo ficou responsável pela ilustração de um ou dois parágrafos do texto lido, com o objetivo de mostrarem o que tinham compreendido daquela leitura.

Durante a execução dessa atividade, fomos questionando algumas crianças a respeito da proposta de trabalhar em equipe e elas se colocaram falando sobre vários aspectos.

"O trabalho fica mais fácil, quando faço sozinho demora mais tempo;

Todo mundo tem ideia e conhecemos mais o colega;

$\mathrm{O}$ trabalho fica mais bonito. Eu estou colorindo melhor porque vejo o meu colega pintando muito bem;

Um pode emprestar o material para o outro;

É mais divertido;

Estou caprichando mais no trabalho porque faço o melhor na frente do meu colega;

Eu vejo o colega desenhar e isso me ensina a desenhar de outra maneira;

Quando estou desenhando sozinha, estou acostumada a fazer do meu jeito e quando estou com o colega aprendo que o mesmo desenho pode ser diferente e assim aprendo a ver a maneira de desenhar do colega".

De acordo com Vygotsky (1995, p. 110), as relações interpessoais são entendidas:

...como condição necessária para a produção de conhecimento por parte dos alunos, particularmente aquelas que permitem o diálogo, a cooperação e troca de informações mútuas, o confronto de ponto de vista divergentes e que implicam na divisão de tarefas onde cada um tem uma responsabilidade que, somadas, resultarão no alcance de um objetivo comum.

Nas colocações dos alunos fica evidente que estão falando a favor de seus interesses e do interesse coletivo. Falar que a tarefa fica mais fácil, que demora menos tempo para fazer, que o trabalho fica mais bonito e a atividade mais divertida torna evidente que esses aspectos colaboram para que a tarefa se torne mais agradável e ao mesmo tempo interessante. A presença do "outro" colabora para que a atividade tenha mais significado real.

A cooperação também se faz presente quando podem emprestar o material do colega, quando falam que todo mundo tem ideia, mostrando que podem se ajudar mutuamente.

Aprender com o outro e perceber que o mesmo desenho pode ser feito de várias maneiras confirma que, na interação entre as crianças é possível produzir conhecimento. 
Ao considerar as colocações dos alunos a favor de seus interesses, estamos colocando-os como centro do processo educacional e desafiando-os a identificarem problemas e criarem propostas para a solução. Com essa proposta, podemos inferir indícios de insubordinação criativa.

\section{Contando para descobrir}

Descobrir a quantidade de carteiras da sala de aula foi o desafio proposto na segunda atividade deste artigo. As crianças tiveram a oportunidade de contá-las individualmente, da maneira que melhor conseguiam entender o cálculo e cada um fez 0 seu registro.

A professora montou uma folha com todas as resoluções diferentes que registraram e solicitou que escolhessem a maneira mais rápida de se calcular o total de carteiras.

$\mathrm{Na}$ imagem abaixo, podemos observar a variedade de respostas que as crianças registraram ao contarem as carteiras da sala de aula.

Figura 1: Registros individuais sobre a contagem das carteiras

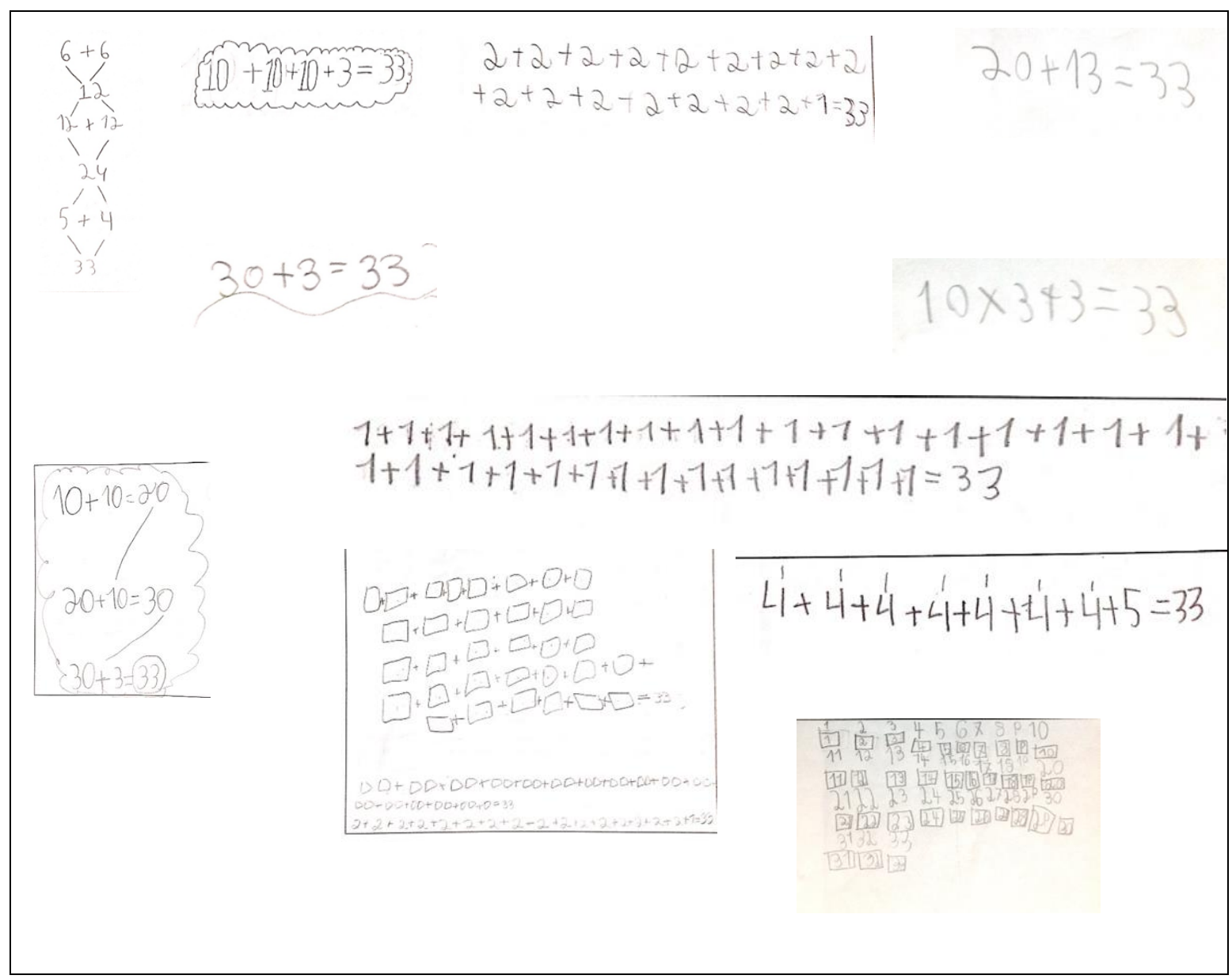

Fonte: Registro da professora 
Podemos observar que alguns alunos representam as quantidades com desenhos, outros representam as quantidades com os símbolos numéricos e de maneira diversificada: somam de um em um ou utilizam quantidades maiores.

Após analisarem essa folha, as crianças foram organizadas em grupos para discutirem qual seria a maneira mais rápida de chegarem ao resultado total de carteiras. As justificativas das escolhas foram as seguintes:

Aluno: "Escolhi $30+3$ porque tem menos números, tem muitas contas que são compridas como $1+1+1+1+1+1+\ldots$ "

Aluno: "30+3 é mais rápida porque já tem o 30 e aí é só colocar +3. Quando tem muitos números você pode acabar colocando números a mais ou números a menos".

Aluno: "30+3 é mais rápido do que 20+13 porque 30 é maior que 20 e é só somar 3 e na outra tem que somar 13".

Aluno: "30+3 é mais rápida porque só tem 2 números. Professora: Então porque não o 20+13 que também só tem 2 números? Aluno: "O 20+13 demora mais para pensar". dá 33"

Aluno: "20+13 é mais rápido porque $20+10$ dá 30 depois e é só colocar mais 3 que

Aluno: "10+10+10+3 porque é mais fácil contar de $10 \mathrm{em} 10$ ".

Aluno: " $10+10+10+3$ porque tem o 10, o 20 e o 30 ".

Figura2: Comparação de registros dos alunos

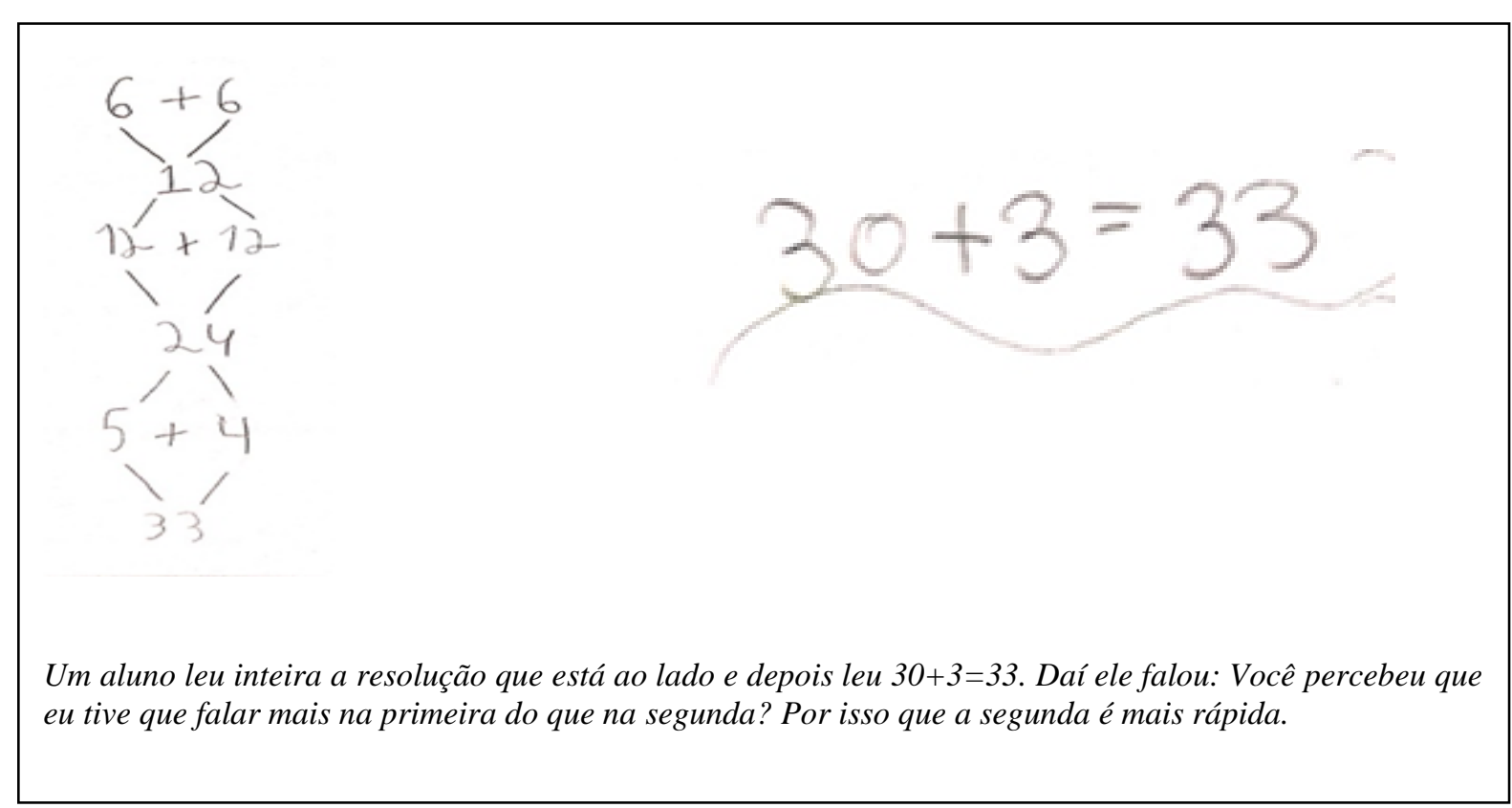

Fonte: Registro da professora 


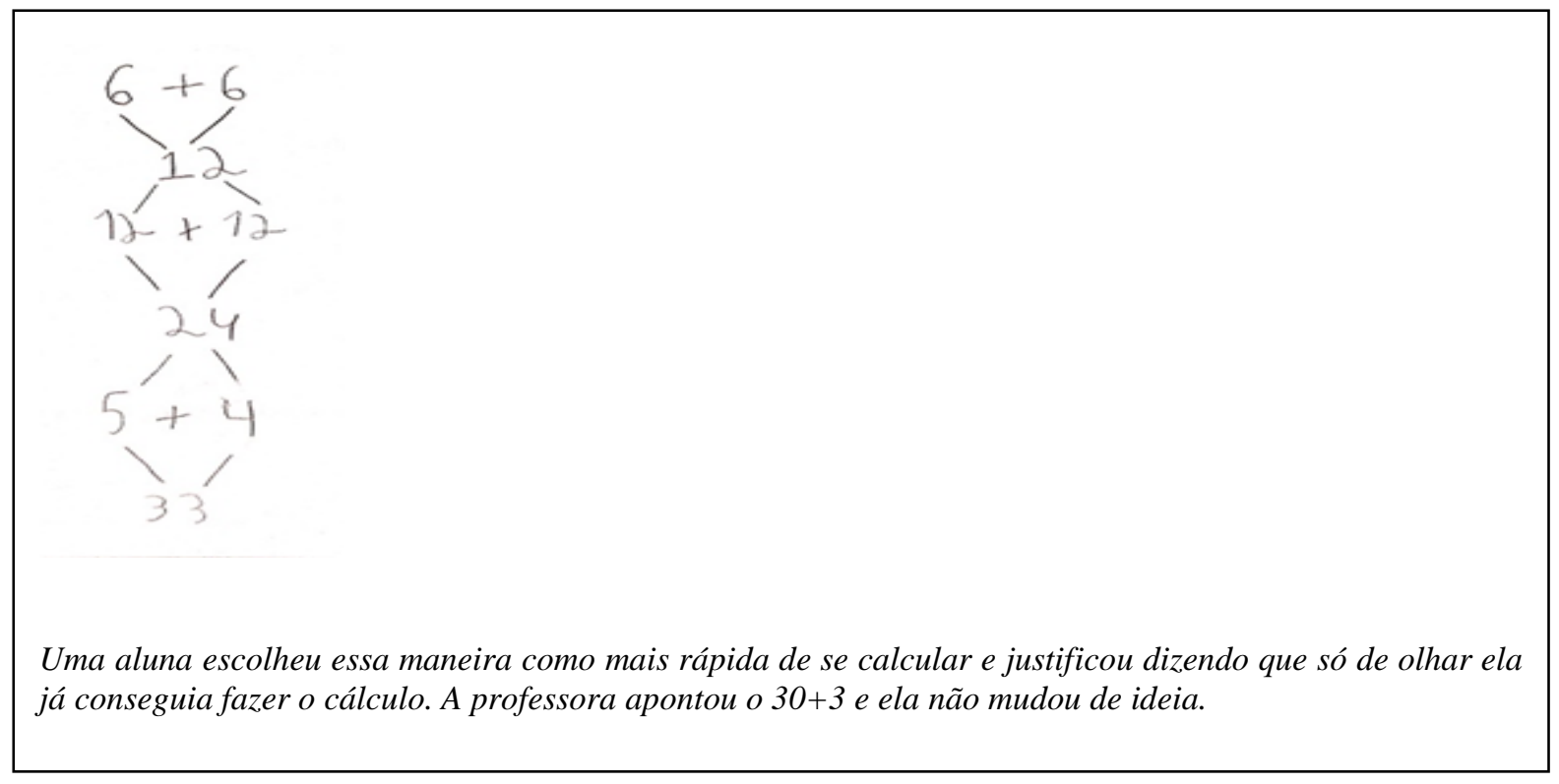

Fonte: Registro da professora

Professora: "Por que vocês mudaram de ideia? Aluna: "A gente estava falando sobre aquele negocinho da conta, daí a gente ficou discutindo sobre aquele negocinho que é $10+10+10+3$ e a gente olhou aquele outro que foi $30+3$ e a gente achou que era mais fácil. Daí eu e a Malu, a gente pensava do outro jeito que $10+10+10+3$ era fácil, só que daí a Vic deu a ideia de fazer $30+3$ e a gente concordou.

As justificativas foram coerentes, pois cada um escolheu a maneira que conseguiu entender. Quando um aluno não muda a sua ideia, mesmo não sendo a escolha da maioria, demonstra estar a favor de seus interesses revelando indício de insubordinação criativa.

A partir das justificativas, algumas crianças observaram que, somar de um em um, pode não ser uma contagem segura, porque existe uma grande probabilidade de errar, pois têm que contar o mesmo número por muitas vezes.

Outras crianças não conseguiram justificar a escolha que fizeram e mesmo após a discussão coletiva, muitas delas não conseguiram mudar de opinião.

É relevante destacar a importância de se proporcionar esses momentos de discussão com mais frequência para que as crianças comecem a aprender a fazer escolhas e justificá-las.

Essa socialização faz com que alguns alunos avancem no sentido de conhecerem outras resoluções e possivelmente perceberem resoluções mais fáceis e rápidas para realizarem cálculos com números maiores.

Quando o aluno se dedica a descobrir como o colega pensou a partir de um registro, tem que levantar hipóteses lógicas que deem significado real para aquela resolução e dessa forma está respeitando como o outro pensou e ao mesmo tempo se sentindo respeitado, pois sabe que também vão buscar entender o seu pensamento para aquela resolução. 
Nesse momento é que as crianças, com a mediação do professor, começam a perceber que podem pensar em suas resoluções e serão valorizadas pela professora e pelos colegas.

Após essa discussão em pequenos grupos, a professora questionou as crianças a respeito de como se sentiram falando para o colega o seu raciocínio, se expondo perante o grupo.

As crianças falaram que, quando estão organizados em grupo, podem ouvir como o colega pensou para resolver um problema, podem ajudar um colega que não fazer a lição e que todos podem errar. Disseram com veemência que não precisa ter medo de errar, porque errando se aprende coisas novas. Parece que foi geral o conforto ao ouvirem esse comentário de uma colega.

Assim sendo, observam-se evidências de que podem surgir aspectos emocionais que interferem no momento da uma exposição no grupo. O aspecto social aparece como um fator inibidor onde se configura a preocupação com o respeito e do que o outro poderá pensar a partir de sua colocação. Quando o grupo relata o que sente quando vivencia uma situação como a descrita acima, os argumentos utilizados por eles podem amenizar esse sentimento de medo. Dessa maneira, nesse caso, o fator social colaborou para um crescimento, para um enfrentamento perante uma situação inibidora.

\section{Considerações Finais}

Ao se referir às narrativas (auto)biográficas como método e fonte de pesquisa, Passeggi (2010) dedica-se sobre a história de vida do narrador como agente e paciente das interações sociais no meio social em que vive.

Dessa maneira, ao narrarem o que pensam perante o grupo, as crianças estão colocando significado no que falam, no que observam, no que sentem e dessa maneira estão agindo em prol de si mesmo e do coletivo demonstrando indícios de insubordinação criativa, caracterizando ações em benefício do outro. Falar sobre o erro demostrou que estavam preocupados com isso e ao mesmo tempo minimizou o sentimento de medo, atenuando a segurança perante os colegas e a professora.

No que se refere à contagem da quantidade de carteiras da sala de aula, o professor precisa valorizar que a riqueza da mesma está em socializar as diversas maneiras de resolução encontradas pelos alunos para resolvê-la. Esse intercâmbio entre os colegas, faz com que possam reconhecer o seu trabalho e o do outro como produção social.

Cada aluno vem com sua experiência relacionada ao conteúdo trabalhado, as suas facilidades e dificuldades e, ao encontrar outro sujeito que demonstra uma resolução diferente da sua para a mesma tarefa, faz com que entenda à sua maneira e que também queira entender como o outro resolveu a mesma situação-problema. Além disso amplia a diversidade de resoluções para aquela situação. Com essas considerações a respeito do 
aspecto social na aprendizagem, reconhecemos com Passeggi (2010) a pesquisa (auto)biográfica:

As perspectivas da abordagem histórico-cultural (...) são ricas em pistas de investigação para apreender as formas como as pessoas se interrogam sobre a construção permanente de si mesmo, de sua relação com o trabalho, com o outro no mundo da vida. Em todos os casos, as pesquisas voltam-se, aqui, para a compreensão dos fatos narrados pelas pessoas como protagonistas da história de si no contexto da história do seu tempo e do seu lugar. A apropriação da história social como história pessoal não seria apenas o objeto da pesquisa (auto)biográfica, mas seu método.

Propiciar momentos em que os alunos possam se colocar perante seus colegas e seus professores, quando o aluno passa a ser o centro do processo educacional e criando propostas para soluções numa situação-problema, nos mostram indícios de insubordinação criativa, onde o professor se assume em favor de seus alunos, para o bem de seus alunos.

De acordo com Freire (2014, p.56) a inconclusão do ser humano nos possibilita a maravilhosa "aventura", que é a educação de todos e todas nós seres humanos.

..."Aventura" entendida como o momento da curiosidade espontânea que vai se fazendo epistemológica, da educação criadora, da ousadia libertadora, da formação da cidadania e da autonomia.

Acreditamos que o ser humano está em constante formação e o educador deve se incluir nesse processo de aprendizagem juntamente com os alunos, buscando proporcionar situações efetivas de trocas e aprendizagens significativas contribuindo para que sejam cidadãos respeitosos, éticos, solidários e insubordinados criativamente.

\section{Referências}

FREIRE, P. Pedagogia da solidariedade. São Paulo: Paz e Terra, 2014.

LOPES, C.; D'AMBROSIO. Insubordinação criativa de educadoras matemáticas evidenciadas em suas narrativas. Anais... XIV Conferência Interamericana de Educação Matemática. México, 2015.

HOOKS, B. Ensinando a transgredir: a educação como prática da Liberdade. Trad. Marcelo Brandão Cipolla - São Paulo: Martins Fontes, p.18, 2013.

MIGNOT, A. C.; SAMPAIO, C. S.; PASSEGGI, M. (Orgs.). Infância, Aprendizagem e exercício de escrita. Nada para a criança, sem a criança: o reconhecimento de sua palavra para a pesquisa (auto)biográfica (Passeggi, M. C.)Curitiba: Editora CRV, 2014. 
MÜLLER, F.; CARVALHO, A. M. A.(Orgs.). Teoria e prática na pesquisa com crianças: Diálogos com William Corsaro. Cap. 3 : Um diálogo com a sociologia da infância a partir da Psicologia do Desenvolvimento. São Paulo: Cortez, p.60, 2009.

PASSEGGI, M. C.;SILVA V. B. (Orgs). Invenções de vidas, compreensão de itinerários e alternativas de formação. Narrar é humano! Autobiografar é um processo civilizatório. (Passeggi M. C.) São Paulo: Cultura Acadêmica, 2010.

REGO, T. C. Vigotski: uma perspectiva histórico-cultural da educação. Petrópolis: Vozes, 1995.

SHUARE, M. A psicologia Soviética meu olhar. São Paulo: Terracota, 2016.

Submissão: 12/06/2017 